\title{
Ethnography in Counseling Psychology Research: Possibilities for Application
}

\author{
Lisa A. Suzuki \\ New York University \\ Jacqueline S. Mattis \\ New York University
}

\author{
Muninder K. Ahluwalia \\ Montclair State University \\ Cherubim A. Quizon \\ Seton Hall University
}

\begin{abstract}
The emphasis placed on prolonged engagement, fieldwork, and participant observation has prevented wide-scale use of ethnography in counseling psychology. This article provides a discussion of ethnography in terms of definition, process, and potential ethical dilemmas. The authors propose that ethnographically informed methods can enhance counseling psychology research conducted with multicultural communities and provide better avenues toward a contextual understanding of diversity as it relates to professional inquiry.
\end{abstract}

Ethnography constitutes a major focus in the psychological literature; however, debates continue regarding the usage of these qualitative methods (Denzin \& Lincoln, 2000a). Despite the fact that ethnographic methods fall within the purview of postpositivism and constructivism-interpretivism frameworks, positivists, postpositivists, and postmodernists currently argue over the definition of ethnography and criteria for evaluating ethnographic work. This article seeks to explore the meanings and manifestations of ethnography, as well as the utility of these methods for counseling psychology. We begin with definitions of ethnography. Next, we delineate the various types of ethnography used in contemporary social science research. Third, we explore concrete strategies for conducting ethnographic research. Ethical concerns and practices to establish validity and trustworthiness are also highlighted. Finally, we provide a discussion of challenges and recommendations for future directions in the use of ethnographic methods in counseling psychology.

\section{What Is Ethnography?}

The term ethnography is derived from a Greek word that refers to a description of a group of people and their way of life (Angrosino, 2002). Ethnography includes both methods of approaching data collection and a philosophical paradigm (Atkinson \& Hammersley, 1994). According to Atkinson and Hammersley (1994), ethnography describes forms of social research that focus

Lisa A. Suzuki and Jacqueline S. Mattis, Department of Applied Psychology, Steinhardt School of Education, New York University; Muninder K. Ahluwalia, Department of Counseling, Human Development, and Educational Leadership, College of Education and Human Services, Montclair State University; Cherubim A. Quizon, Department of Sociology and Anthropology, Seton Hall University.

Correspondence concerning this article should be addressed to Lisa A. Suzuki, Department of Applied Psychology, Steinhardt School of Education, New York University, 239 Greene Street, 4th Floor, New York, NY 10003. E-mail: las1@nyu.edu on (a) exploring the nature of particular social experience, (b) gathering and using unstructured data, (c) using a relatively small number of participants, and (d) interpreting the meanings of human behavior. Although interviewing and observation are the techniques most often associated with ethnography, any method of deriving information may be used in ethnographic research (e.g., archival exploration, survey; Angrosino, 2002).

The classic image of the ethnographer is a researcher who enters into the community and becomes immersed in the culture-for example, lives among the "natives." Although ethnographic methods were reported in 15th and 16th century texts that reflected "Western interest" in understanding "other" people and communities, it was not until the late 19th and early 20th centuries that modern ethnography was identified (Atkinson \& Hammersley, 1994). The now-classic works of pioneers in ethnographic fieldwork such as (Boas 1888/1964), Cushing (1920), and Malinowski (1922), helped to spawn the formation of contemporary ethnography within sociocultural anthropology. Their work emphasized the importance of participant observation and fieldwork as means to obtaining meaningful information about individuals within the communities being studied (Tedlock, 2000).

Ethnography leads to the creation of narratives - stories that are embedded in multiple contexts (e.g., historical, economic, social; see Hoshmand, 2005, for a discussion of narratives). The integration of contextual information is critical to obtaining an accurate understanding of various cultural groups. In the absence of such a framework, the data would be interpreted on the basis of the researcher's uninformed perceptions.

Although ethnographers rely on myriad techniques, critical to any ethnographic process are participant observation, fieldwork, and prolonged engagement. The researcher's academic discipline has a powerful impact on shaping the meanings and manifestations of observation, fieldwork, and engagement. For example, many psychology texts define prolonged engagement in terms of a 6-month to 2-year investment. In contrast, anthropologists often recommend a minimum of 1 year. 
Finally, ethnography also recommends a particular relationship between researchers and the communities that they study. Although there are vibrant debates among ethnographers about the nature and limits of this relationship, Tedlock (2000) articulated the commonly accepted view of the ethnographer's relationship to communities and community members. Tedlock stated that "ethnographers are expected to maintain a polite distance from those studied and to cultivate rapport, not friendship; compassion, not sympathy; respect, not belief; understanding, not identification; admiration, not love" (p. 457).

It is important to note that there are often difficulties in establishing and maintaining distance, given prolonged contact with participants and the close relationship that may need to be established in order for researchers to establish trust with participants. Despite this, the ethnographer is expected to establish and maintain substantive and genuine relationships with participants, be ever mindful that their goal is to create scientifically rigorous scholarship, and be careful not to cross lines of intimacy that would compromise the integrity of their scholarly work.

The term ethnography is often used interchangeably with the term community-based research (see Fantuzzo, McWayne, \& Bulotsky, 2003; and Israel, Shulz, Parker, \& Becker, 1998, for a discussion of principles of community-based research). Although there are points of synthesis between these two methodologies, the methods are not synonymous. Unlike ethnography, communitybased research is neither explicitly nor necessarily concerned with culture, cultural processes, or meaning. Although communitybased researchers often collect quantitative as well as qualitative data, ethnographers tend to rely largely on qualitative data. Further, the lexicons of these two methodologies are different. Indeed, community-based researchers speak of "partnership" and "mutual goals," whereas ethnographers speak of "subjectivities" and "guesthood." Whatever differences may exist between them, the reality is that there is a symbiosis inherent within these methodologies. As is the case with ethnography, community-based research is deeply attentive to the complex ways in which social position and social identities (e.g., class, gender, ethnicity, sexuality, and so forth) shape both people's lived experience and the research enterprise. Both ethnographers and community-based researchers have launched substantive debates about the nature of authentic and respectful relationships, the meanings and manifestations of power in the relationship between researcher and researched, and the meanings that people construct about the world.

\section{Types of Ethnography}

The Handbook of Qualitative Research (Denzin \& Lincoln, 2000a) identifies a number of types of ethnography including life history, memoir, narrative ethnography, auto-ethnography, fiction, applied ethnography, and ethnographic decision modeling. Life history reflects individual participants' experiences as well as the context of various life events that have impacted their lives (e.g., biographies). Ethnographers may collect a number of life histories and then create a "rhetorical figure of synecdoche, in which a 'representative' individual is selected and made to stand for an entire culture" (Tedlock, 2000, p. 459). The memoir is typically a report of an ethnographer's journey in the field (i.e., in a particular community under study). The narrative ethnography is an integration of the life history and memoir. Like the life history, the narrative ethnography focuses on the lives of participants and includes the ethnographers' own experiences, perceptions, and emotional reactions. Auto-ethnography focuses on an autobiographical account of an individual's life and research (see Ponterotto, Casas, Suzuki, \& Alexander, 2001, for examples of counseling pioneers' auto-ethnographies). Applied ethnography often refers to research that advocates social change and increased intercultural understanding. Other less formal ethnographic works include travelogues, chronicles, and diaries. There are also fictional ethnographies that may take the form of short stories, novels, and plays. More contemporary methods such as ethnographic decision models are based on qualitative methods using grounded theory and content analysis (Beck, 2005; Ryan \& Bernard, 2000) and are derived from exploratory data, model building, and testing.

In contrast to classic anthropological ethnographies that examined entire societies, contemporary ethnographies have become much more localized, with small-scale theories focused on particular problems and situations (Denzin \& Lincoln, 2000a). Despite the conflicts and changes that emerge out of different philosophical approaches to ethnography, ethnographic methods have had, and continue to have, a major impact on topics often considered to be within the purview of counseling psychology (e.g., vocational development). Stewart (2003) advocated the usage of ethnographically informed methods in psychology. She noted that ethnographic methods are "compatible" with the "methodological values" of most psychologists (p. 3). Her work supports the idea that ethnographically informed methods enable researchers to place the experiences of individuals within a social context.

Although researchers in social work and in social and community psychology advocate the use of ethnographic methods, there is a paucity of published ethnographies in counseling psychology. Although the research traditions in counseling psychology do not appear to lend themselves to the level of prolonged contact, fieldwork, and observations discussed in the anthropological literature, it is clear that ethnographic methods inform our way of conducting qualitative research. Counseling psychologists' focus on relationship and integration of contextual variables with respect to culture is advocated and evidenced throughout much of the literature in our discipline. Greater efforts are needed in counseling psychology to incorporate ethnographically informed research methods in studies with diverse communities.

\section{Conducting an Ethnography}

There are a number of steps in conducting ethnography: (a) topic selection, (b) theoretical and conceptual framework, (c) researcher stance, (d) participant observation and fieldwork, and (e) synthesis and sharing of ethnographic data.

\section{Topic Selection}

The process by which researchers select their topics varies. Studies may emerge out of a researcher's predetermined interest, out of collaborative/partnership dialogues with members of the community, and/or they may be commissioned by institutions or entities that are interested in learning about (or documenting) a particular aspect of community life. 
When deciding on an ethnographic subject, researchers must engage in critical self-reflection centered on a number of key questions: What are my personal motivations for studying this topic? Why this place? Why this community? Why these people? How, if at all, will this study benefit me personally? (e.g., Will the study of an "exotic" community enhance prospects for tenure?) What cultural or personal perspectives and biases do I bring to this process, and how might those shape the various phases of this work (e.g., conceptualization, attention to data, interpretation, relationships with community members)? Why am I doing this research at this historical, personal, or professional moment? In what concrete ways will the community be benefited or harmed by this work? Failure to seriously attend to these questions can lead to classical problems in which ethnographers create or recreate inaccurate, stereotypical, or exoticized views of communities-views that may misrepresent or endanger the welfare of people under study.

These questions must be addressed by all researchers but are particularly salient when the researcher is not a member of, and/or has no direct relationship with, the community being studied. Suzuki, Prendes-Lintel, Wertlieb, and Stallings (1999) faced these questions in their qualitative study to document retrospectively the relocation experiences of unaccompanied Cuban children in the United States after Castro took over the Cuban government. The research team was composed of one member of the Cuban community who had herself been an unaccompanied minor during this event, a Japanese American, a Caucasian American, and an African American. The research process involved spending time with community members (in Miami, FL); interviewing participants, their parents, and offspring; attending a reunion; visiting the refugee relocation camp with community members; and so forth. Despite over 1 year of contact with this community (though the contact was periodic), and despite the warm welcome from the hosts, questions arose as to whether community members could better tell and document their own story directly rather than through the lenses of the outside researchers. As noted by one team member,

I am reluctant to view myself as anything more than a mouthpiece to the experiences of this group. I am constantly humbled at the level of trust this group has given me over the years. ... In the beginning there was not much out there being written or studied with regard to this group. ... I believe that my hesitancy is based upon the assumptions that I have made with regard to my belief that members of the community possess a depth of understanding that cannot always be captured by an outsider. (p. 127)

A general discussion of the benefits and limits of the insider versus outsider perspectives is provided in the Researcher's Stance section of this article.

The effort to tailor and address research questions is complicated by at least two factors. First, because ethnography is a description and interpretation of a cultural or social group or system, it is important for the researcher to explicitly articulate the definitions of culture that guide their ethnographic work. Geertz's (1973) definition of culture is often used as a frame for ethnographic studies. Geertz stated that culture "denotes a historically transmitted pattern of meanings embodied in symbols, a system of inherited conceptions expressed in symbolic forms by means of which men [sic] communicate, perpetuate, and develop their knowledge about and attitudes toward life" (p. 89). This and similar definitions of culture are important in that they focus on culture as an inherited system of meaning-making that shapes all facets of life. This meaning-centered definition allows researchers to avoid the common error of equating race, class status, and ethnicity with culture.

Second, given the focus on culture in ethnography, in defining and addressing their questions researchers must clearly specify who is to be considered a member of the cultural group of interest and must determine the bases on which inclusion and exclusion should be made. For example, in Mattis's ongoing study of a particular low-income African American community, questions emerged about who should be defined as African American (e.g., only people who are multigenerational Black Americans, AfroCaribbeans, Afro-Latinos, anyone who self-defines as Black) and who should be included as a member of the community (e.g., people who live in the central low-income housing complex, people who shared temporary residence with friends or family, or people with a sustained history of residence in a particular geographic area). Researchers often make independent decisions about these parameters. However, such decisions must be made in conjunction with the group or culture being studied. It must be noted here that concerns have been raised as to whether the ethnographer creates community by virtue of selecting a group to study (Marcus \& Fischer, 1999).

When ethnographers study culture, they attend to three aspects of the human experience: cultural behaviors (what people do), cultural language (what people know and how they describe their world), and cultural artifacts (things people make or use; Spradley, 1980). Ethnographers must decide which of these aspects of experience will be most central in the study and what strategies will be used to access these aspects of culture. It is important that ethnographers remain aware that the complexity of the human experience lies in the reality that people can and do hold seemingly (or explicitly) contradictory perspectives on any given topic. As such, researchers must seek out complicating or contradictory information within and across each domain of cultural life. Ethnographers also must think critically about how these various pieces of synthetic as well as contradictory information will be integrated in the analysis and interpretation stages. Having deliberately sought out contradictory or alternative sources of information, the ethnographer must both resist and negotiate the urge to construct an artificially coherent story from complex data and strive to analyze whether there are patterns that may be explained through contemporary theoretical perspectives. The stories that researchers tell must effectively reflect the messy, complicated, and dialectical reality of people's thinking and behavior. Researchers also must establish heuristics that will help them determine whether the behaviors, language, and icons that they observe are functions of culture, community, family, personality, or contextual factors.

\section{Theoretical and Conceptual Framework}

One point of debate among ethnographers centers on the extent to which ethnography should be theory driven. Sanjek (2002) suggested that ethnographers must identify some significant theoretical bases to which their research is addressed. Theory, from this perspective, directs the ethnographer to a place to begin the re- 
search process. In contrast, grounded theory asserts that delineating people's lived experience (Fassinger, 2005) requires entering the community sans theory in order to see and hear participant perspectives, document, and build theory from the ground up. This approach suggests that by minimizing or rejecting a reliance on theory, the researcher is better able to avoid practices of cultural dominance and build theories that genuinely reflect people's lived experience. Our perspective is one of flexibility given that some studies warrant a more theoretical grounding, whereas others clearly indicate the need for open exploration.

A conceptual framework explains "either graphically or in narrative form, the main things to be studied-the key factors, concepts, or variables - and the presumed relationships among them" (Miles \& Huberman, 1994, p. 18). Conceptual frameworks can help to elucidate the assumptions that underlie the research and are not necessarily theoretically based. The extent to which these assumptions are based on the ethnographer's personal experience and professional training must be acknowledged and monitored because this can introduce unintended bias if not checked (see the Researcher Stance and Rigor and Trustworthiness sections of this article).

Once research questions have been identified, attention must be given to how terms are defined and operationalized, as this will influence the findings of the study. It is important that the community play a role in shaping definitions of key terms. Indeed, researchers are often surprised to learn that their definitions of terms have little relevance to, and little in common with, the meanings held by community members. This situation is, in many cases, to be expected given that the researcher's language is not equivalent to that of the participants.

Finally, when conducting ethnography, attention must be given to the intended audience of the work. Consideration of the consumers and stakeholders involved in the work is critical because they will determine in part what information the researcher perceives as most pertinent. For example, the researcher may place greater importance on content areas of interest to academics or funders, whereas participants may place greater value on the interaction, process, and benefit to the community.

\section{The Researcher's Stance}

Ethnographers are neither invisible nor neutral (Fontana \& Frey, 2000). They are participants in the interactions and communities that they study. It is critical, then, that researchers remain aware of their own social identities and how these may impact the process of inquiry. For example, prior to engaging in the research process, the researcher must consider the potential impact of his or her personal and group history, gender, class/caste, race, skin color, social attitudes, biases, and so forth. These personal characteristics shape the process of inquiry, making all qualitative research a multicultural process (Denzin \& Lincoln, 2000b). For example, an Arab male researcher or an African American woman researcher with dreadlocks conducting ethnographic work in contemporary America may find themselves to be objects of suspicion and harassment, depending on the community in which they are working. No matter what degree of similarity exists between the social identities of the researcher and participants, differences will always be present that need to be attended to in the process of ethnography. The researcher must attend to issues of difference and power with the participants and community. Thinking ahead about potential dynamics in the relationship and developing a plan with respect to how power differentials will be negotiated and accounted for throughout the research process (e.g., between researcher and community member, among community members) is essential.

In considering her own social identity and its impact on her work, Pipher (2002) began her study of refugees with a description of her childhood and her experiences in growing up in the Midwest:

My view of reality is dependent on my Nebraska perspective. As I write this, I am a wife, mother, and a grandmother. I was raised Methodist although I am now Unitarian. I am middle-class, middleaged, and very ordinary in most ways. I have lived in the Midwest almost all my life. (p. 12)

Having acknowledged her own identity, Pipher noted the difficulties in writing about "others." She states, "Writing about people from other cultures is fraught with social peril. Sentimentalism or romanticizing can be insidious forms of dehumanization. Generalizations about ethnic groups can easily become stereotypes" (p. 17).

Pipher reminds us that monitoring the impact of one's own "social location" (i.e., social identities to which people adhere [such as class, race, gender] as well as positions in social hierarchies that they occupy as a result of those identities) is imperative throughout the process of ethnography. Critical attention to social location can help to shed light on potential biases. It is to be noted, however, that it is not sufficient for researchers to simply articulate their social identities; they must analyze the ways in which those identities inform their conceptualizations, methods, and interpretations.

A core debate in the field of ethnography centers on the relative value of the insider versus outsider perspectives. Traditionally, ethnographers have operationalized "objectivity" in terms of one's stance as an outsider. Implicit in the notion that the outsider stance grants objectivity is the assumption that people cannot know or study themselves. To a large degree, the humanities and social sciences are uncritically steeped in the culture-bound perspectives that see objectivity as possible, necessary, and desirable and that equate objectivity with interpersonal distance. The extent to which distance is useful, necessary, or possible is a matter of debate. In fact, contemporary feminist anthropologists have suggested that intimacy and love may be both inevitable and healthy outcomes of ethnographic work (Ulysse, 2002).

It is important to note that outsiders may not be familiar with the subtle nuances of the language of the community and may not have a foundation of trust with community members. In addition, the danger of conducting work as an outsider is that the researcher may come to be seen as the authority or expert on other people's lives and this may lead to replication of social and political dynamics. Ethnographers who position themselves as "objective outsiders" (and who concomitantly insist on viewing participants as objects to be observed) may create and/or reify power dynamics that are limiting and/or oppressive. For example, low-income and ethnic minority community members may experience the use of observation strategies as akin to dangerous and dehumanizing strategies of surveillance to which they are subjected by the police and other agents of social control. On one hand, a benefit of an 
outsider stance is that one's naiveté can lead one to ask questions that might seem obvious to an insider but are crucial to the explication of the topic of interest.

The benefit of the insiders' perspective, on the other hand, is that insiders are intimately familiar with the language and customs of their own community (e.g., know who to talk to and how to approach potential participants). Therefore, they may be able to access information about the community more readily. Given their membership in the community, however, insiders' approaches to the research and their interpretations of findings may be influenced by their social location and personal experiences. This may prove to be a limitation given that a particular insider's perspective may be at odds with other members of the community.

In order to maximize the benefits and minimize the limitations of the insider-outsider perspectives, it is critical that researchers engage in a self-reflection process, continuously questioning interpretations and considering alternative explanations for findings (i.e., look for discrepant data). In addition, ethnographers must engage in practices that will ensure trustworthiness (see the Trustworthiness and Validity section).

\section{Participant Observation and Fieldwork}

The work of ethnography is grounded in genuine relationship, and researchers must behave in ways that preserve the integrity and humanity of their study participants and collaborators. In order to enter into the private space of a community, one often needs to establish and maintain a relationship with a host or a supportive "informant." This individual must be a member of the community, someone who has credibility in the community, who is knowledgeable about the domain of life in which the researcher is interested, and who is able to bridge the divide between tacit and explicit knowledge. The ethnographer must also be clear on the nature of his or her relationship to this informant. The work of discovery depends, in large part, on the work that is done to establish rapport and to gain as well as sustain trust.

Collecting empirical materials. Ethnographers rely on a wide range of data, including interview, archival, and observational data. The focus and methods of recording and analyzing observations need to be determined prior to fieldwork so that the behaviors can be documented as they appear. As noted earlier, personal biases that may potentially shape the outcome of the observation need to be monitored. In addition, it is important that researchers remain aware of the dynamic nature of the observational process. As Tedlock (2000) noted, ethnographers "both experience and observe their own and others' coparticipation within the ethnographic scene of the encounter" (p. 464). Thus, Tedlock noted that, in addition to participant observation, one must also attend to observation of participation.

The researcher must decide whether he or she will work alone or with (insider) others to conduct observations. Whether alone or assisted, however, researchers must think critically about the contextual factors (e.g., location, identity, time of observation) that might shape what they observe and how they interpret their observations.

Training interviewers, informants, and interpreters. All parties involved must be clear about the nature of the relationship. The researcher may adhere to an apprenticeship model in which he or she is a novice being mentored by the consultant (i.e., participant) or expert community informant. This approach creates a sense of equality and collaboration in the relationship between researcher and community members (Tedlock, 2000) and changes the research dynamics of the researcher and the participant into one of teacher and student, apprentice and mentor. Researchers often envision themselves as employers and their interpreters, interviewees, and informants as employees who are engaged in a contractual relationship. However, interviewers, interpreters, and informants often experience themselves as team members, equals, or as experts with unique contributions to make and with a special interest in protecting the interests of a community of which they may be members. The employer-employee and the team member-expert models imply radically different power relationships. Open dialogues about the nature of the relationship and each person's expectations are important prior to beginning the work and throughout the various stages of the research.

In the absence of open dialogues and agreements, collaborators may exercise levels of influence that are uncomfortable for the researcher. Interpreters, for example, may provide summaries rather than verbatim translations of interviews. Informants, interpreters, and interviewers may also deliberately or unwittingly change the content of the questions that are asked or make unilateral decisions about what information is important, relevant, or necessary. For these reasons, addressing issues of language mastery-proficiency is key to good fieldwork. Certainly, researchers must be both direct and explicit in naming what they need or expect from interviewers, informants, and interpreters. However, the extent to which the researcher's expectations are met is constantly negotiated and renegotiated over the course of a relationship that honors the expertise of the collaborator while seeking to meet the needs of the researcher.

The fact that one has made one's expectations explicit (and the fact that no overt objection has been voiced) does not mean that one's collaborators have agreed to the conditions outlined by the researchers. Collaborators who are members of vulnerable communities may use subversive strategies of power to protect those communities. These strategies of protection may be experienced as destructive by researchers. That is, interviewees, informants, and participants may lie, change questions, invent stories, or reinterpret information. Researchers must learn to recognize these as "stop" strategies (i.e., as efforts to prevent the researcher from entering into areas that may leave the community vulnerable) and must use these moments as opportunities to either engage in dialogue or to rethink the focus and direction of the work (Fantuzzo et al., 2003; Israel et al., 1998).

It is important to note that collaborators' social identities will shape their work with researchers and with the community. Informants, interviewers, and interpreters may be individuals who are of higher or lower status (e.g., socioeconomic status, racial status) than the researcher. How these individuals relate to the researcher, and the nature of these collaborators' perspectives on the topic of study, will inevitably shape the content and direction of the ethnographic work. For example, while conducting pilot work in East Africa, Mattis (Mattis \& Dickerson, 2001) worked with one informant who was a member of the nation's educated elite. This woman's social status and material wealth placed her in a higher socioeconomic status than both the researcher and the women who were to be the focus of the study. As such, although this informant was able to provide entrée into communities of poor women, her 
elite class status informed her perspectives on what were acceptable and respectable topics of conversation and on what was acceptable for the researcher to hear and know. This informant moved between a sense of shame about the appearance, experiences, and speech patterns of women who were the focus of the study and an awareness that the objects of her shame ("poor women") were invaluable in that they gave her access to an American researcher whose American-ness and title (Dr.) reinforced her status as a member of her nation's elite and provided access to gains (e.g., opportunities to travel) that she presumed might ultimately come from that association. These complexities reinforce the importance of developing relationships with several collaborators. Taken together, these points also suggest that researchers must think clearly about how much room research team members will have to shape the direction of the work.

Entry and sampling frame. Prior to entering any community, the researcher must address the following questions: Who are the people/communities of greatest interest? Who is best suited to establish contact with the community? How will initial contacts be established with the community? How will trust be earned and maintained? How will the research be represented and explained to the community? and How will the identity of the researcher be addressed?

In assessing the sampling frame, researchers should be clear on the number of people they will need to interview or observe in order to achieve "saturation" (i.e., point in the research process where major themes are consistently repeated and no new themes are emerging). Researchers also must decide on the factors that they will need to consider in order to obtain the most complex picture of the phenomenon of interest. That is, they must decide on the extent to which such factors as gender, social class, skin color, education, place of residence, or other variables might be used to create important subgroups of people whose perspectives on the particular topic of interest might differ.

Data collection. Sanjek (2002) noted that the process of ethnography begins with "situated listening" (p. 196), whereby the researcher is located in the community and is engaged in observational work and in gathering narratives from community members. The fieldworker enters into natural conversations with members of the community and gradually shifts the topic of conversation to his or her own areas of interest. This process becomes smoother as the ethnographer becomes more competent within the community being studied (e.g., more culturally competent). As this process continues, the ethnographer may ask more pointed questions to obtain more precise information, although caution must be used given that taking control of the process may make participants uneasy. Sanjek reported that, after a few months, fieldwork interviews may begin, though the timing of the process is better determined by the researchers and their collaborators.

The interview process also has its own flow and course. Interviews begin generally and become more focused over time. In later interviews, the ethnographer may assert control and introduce topics in which participants are asked to elaborate and provide their point of view. In the most focused form of the interview, the ethnographer may use an interview schedule or questionnaire for which the objective is to obtain particular pieces of information with respect to predetermined categories.

As the ethnographer listens, she or he may initially record "scratch notes" (Sanjek, 2002) that will form the basis of the field notes and corresponding analytic memos. Because the memory of experiences may fade quickly, scratch notes must be examined quickly or they may grow "cold." Sanjek (2002) cited the usage of "headnotes" (i.e., "stored memories and interpretations that arise from direct participant observation as filtered by the ethnographer's overall theoretical stance" [p. 197]), which help in the creation of field notes.

\section{Synthesis of Ethnographic Data}

A principal challenge facing ethnographic researchers is how to weave together the various sources (e.g., archival, observational, interview, artifactual) and domains (e.g., cognition, behavioral, affective) of cultural information that they have gathered. Given ethnography's focus on meaning, experience and culture, ethnographers must determine the extent to which the study's findings represent matters of culture, community, family, personality, or context. Ethnographic researchers must clearly and systematically document how they arrive at their conclusions. Finally, researchers must examine the ways in which their social position, assumptions, and approaches may have informed the research process and research findings.

It is important to consider what role the community will have in shaping the analysis, interpretation, and reporting of the data. In this regard, it is crucial for researchers to question how they will establish an appropriate balance between their voices and the voices of the community members. As the work comes to a close, it is important for researchers to determine how they will share their findings with the community and the individual participants. For researchers who were engaged in partnerships with the community, it is critical to think about how to make the work and its findings useful to the community. That is, researchers must be clear on the skill sets, material goods, or resources that they can and will gift to the community. Finally, researchers must consider when and by what process to bring closure to their relationships with the community and with the people who facilitated the research.

\section{Ethics in Ethnography}

There are a number of ethical issues that need to be attended to prior to and concurrent with the research being conducted (see discussion of ethics in Haverkamp, 2005). For counseling psychologists, the American Psychological Association's (2002) Ethical Principles of Psychologists and Code of Conduct provides foundational guidelines for research. For psychologists engaging in ethnography, however, the Code of Ethics of the American Anthropological Association (1998) is essential as an additional ethical guide. Thus, both ethical guidelines should be used to guide choices and practices. Because these codes and Haverkamp provide more extensive overviews of ethical concerns, in this section we only briefly outline concerns to which ethnographers need to attend. First, in ethnographic research, ethical concerns arise in the recruitment of research participants, informed consent, confidentiality, protection from harm, deception, dual roles of researcherclinician, and ownership and interpretation of data (Cieurzo \& Keitel, 1999). Second, important ethical considerations must be made with regard to collaborators (e.g., informants) in ethnographic work. Spradley (1979) noted that the ethnographer must 
inquire about the interests and concerns of informants and must safeguard the informant's rights, interests, and sensitivities. Research objectives must be communicated clearly to informants prior to the start of the research and continue throughout engagement with the community. Third, issues of confidentiality and privacy must be respected. Simply changing names, places, and other identifying information may be necessary, but not sufficient, to protect the identity of informants. This is especially true in studies of small, close-knit communities. Fourth, it is the researcher's responsibility to provide informants with a beneficial return. The accessibility of eventual products (e.g., reports, articles, books, performances) to the community is imperative. Finally, the researcher must be cognizant of what information is off limits. This is done by respecting the "nos" (e.g., statements of resistance) offered by participants and by working with the gatekeepers and informants, as well as through observations and immersion at the site (see Fantuzzo et al., 2003).

\section{Trustworthiness and Validity Concerns}

As the interest in ethnography has grown in disciplines such as counseling psychology, so too has the criticism of the approach. Denzin and Lincoln (2000b) asserted that, as an intellectual technique, ethnography faces three areas of crisis: representational, legitimation, and praxis. The representational crisis centers on debates about the veracity of ethnographers' claims that they directly capture lived experience. Critics note that experience is created in the social text written by the researcher. The crisis of legitimation centers on critiques of the rigor, validity, reliability, and generalizability of ethnographic approaches. Ethnographers have been criticized for generalizing findings to entire societies on the basis of the study of only a few community members. The crisis of praxis emerges out of challenges regarding the implications of shifting the ethnographic enterprise from passive and objective observation to more action-, participatory-, and activistoriented research strategies.

Questions naturally arise regarding the researcher's representation of the participants. These questions may include, Are the researcher's interpretations valid? and How is the validity documented? (see Morrow, 2005). Sanjek (2002) identified two key mechanisms for establishing validity: (a) theoretical candor-that is, exploring how well the researcher addresses the theories that influenced the fieldwork process and (b) explicit depiction of the fieldwork path - that is, providing a discussion of the number of informants and their relationship to the overall population. In addition, there are four validity tests that may be useful in ethnography (Maxwell, 1996). These include (a) having "rich" data, (b) searching for discrepant evidence, (c) triangulation, and (d) quasistatistics. Rich data are thorough and complete and provide a "full and revealing picture" of the phenomenon being studied (Maxwell, 1996, p. 95). Searching for discrepant evidence involves examining the data for areas of participant disagreement with respect to potential themes. Triangulation refers to the use of a variety of methods to collect information from different sources (i.e., interviews and observations). Though triangulation does not eliminate problems of validity, it reduces the risk of systematic bias and an overreliance on any one method of data collection and data source. Quasi-statistics involve the use of simple numerical results derived from the data that allow the researcher to assess both the amount of supportive evidence and the discrepant cases.

In order to reduce the negative effects of researcher bias in ethnographic work, researchers may also do member checks (Maxwell, 1996; Miles \& Huberman, 1994; Seidman, 1998) by systematically getting feedback from the participants so as to ensure they do not misinterpret the participants' understanding of their own experiences. Chambers (2000) advocated that criteria of utility be applied to establish the reliability and validity of applied ethnographic studies. In particular, he noted that results of the study should be accessible, relevant, significant, and credible. In addition, results should reflect the interests of stakeholders in terms of what "could be" rather than what currently exists.

\section{Challenges Associated With Ethnographic Research}

There are a number of reasons why conducting ethnographic research is challenging to many professionals, including counseling psychologists (Creswell, 1998). First, researchers interested in conducting ethnographic work must have a firm grounding in cultural anthropology and possess knowledge of the socialcultural system of the community being studied. Second, the need for prolonged engagement in fieldwork means that data collection time is extensive. This investment of time is often difficult for many academic researchers in counseling psychology whose future employment (i.e., tenure) often depends on productivity (number of publications). Creswell (1998) also noted that, given the depth of relationship between the ethnographer and cultural informants, there is a danger that the researcher will "go native" and compromise the rigor and accuracy of the study (p. 61). Pipher (2002), in her study of refugees in Nebraska, wrote about the difficulties of keeping objective research boundaries:

For a while I was so involved with the lives of the sisters that (mother) told me that her daughters were now my daughters. I was touched that she was willing to give her daughters away so that they could advance. I tactfully suggested that we could share her daughters, but that she would always be the real mother. (p. 35)

In the context of this study, Pipher became a confidant of the sisters. She provided them with encouragement, support, and access to resources. In addition, she helped the families in her study to negotiate within their new environment. This tendency to "go native" may be especially salient among counseling psychologists given that their clinical training is designed to obtain details about the lives of clients and to use this information to establish an intimate, transformative, therapeutic relationship.

In many ethnographies, the narratives are written in a literary, almost storytelling approach, an approach that may limit the audience for the work and may be challenging for authors accustomed to traditional writing styles that are more consistent with academic social science research (Creswell, 1998). For example, most psychological literature is written in the third person to convey the objective stance of the researcher. Ethnographies, in contrast, are often written in the first person, reflecting the personal meanings constructed by the community members and the impressions of active engagement of the ethnographer.

\section{Future Directions in Ethnographic Methods}

Although the limitations are many and the challenges great, ethnographically informed methods in counseling psychology 
show great promise. The immersion in a community provides invaluable relationship building and unparalleled depth and breadth in access to information. As was discussed earlier, the challenges for academic psychologists engaged in ethnography are not insignificant, and they cannot be dismissed. If ethnography is to gain prominence as a method of inquiry among counseling psychologists, there must be a paradigmatic shift in the field of counseling psychology and a real investment in cross-pollination of disciplines by academic institutions.

Anthropological ethnographies in the past have often proposed to examine aspects of "stable" communities of "others." Today, the disciplines of counseling psychology and anthropology share interest in communities where individuals are experiencing shifts in their identities, roles, and functions as a result of macrolevel social and political changes. Thus, counseling psychologists may be particularly well poised to explore the nuances of conducting ethnographies in complex environments (e.g., urban contexts) where the boundaries of communities are often difficult to determine and where frequent migrations of families because of the absence of affordable housing or the unavailability of jobs may complicate the work of ethnography.

The challenges to conducting ethnography, as noted by Creswell (1998), have led some researchers to modify how they apply these methods in current research. For example, many applied ethnographers are working as part of research teams collaborating with colleagues operating from a quantitative standpoint (Chambers, 2000). This has led to greater breadth in methodological expertise and enhanced the discussion and cross-fertilization of research perspectives. Use of combined methods (qualitative and quantitative) is an outgrowth of this process of cross-fertilization. As noted earlier, ethnographically informed methods of research have great potential to enable counseling psychologists to implement aspects of this qualitative venue to enhance the contextualization of research addressing the needs of diverse populations.

The authors suggest the following texts to gain further understanding of ethnography: Handbook of Qualitative Research (Denzin \& Lincoln, 1994, 2000a), Handbook of Methods in Cultural Anthropology (Bernard, 1998), and Doing Cultural Anthropology: Projects for Ethnographic Data Collection (Angrosino, 2002).

\section{References}

American Anthropological Association. (1998). Code of ethics of the American Anthropological Association. Retrieved May 10, 2004, from http://www.aaanet.org/committees/ethics/ethcode.htm

American Psychological Association. (2002). Ethical principles of psychologists and code of conduct. Retrieved May 10, 2004, from http:// www.apa.org/ethics/code2002.html

Angrosino, M. V. (2002). Doing cultural anthropology: Projects for ethnographic data collection. Prospect Heights, IL: Waveland Press.

Atkinson, P., \& Hammersley, M. (1994). Ethnography and participant observation. In N. K. Denzin \& Y. S. Lincoln (Eds.), Handbook of qualitative research (pp. 248-261). Thousand Oaks, CA: Sage.

Beck, K. A. (2005). Ethnographic decision tree modeling: A research method for counseling psychology. Journal of Counseling Psychology, 52, 243-249.

Bernard, H. R. (1998). Handbook of methods in cultural anthropology. Thousand Oaks, CA: Sage.

Boas, F. (1964). The central Eskimo. Lincoln: Bison Books and University of Nebraska Press. (Original work published 1888)

Chambers, E. (2000). Applied ethnography. In N. K. Denzin \& Y. S.
Lincoln (Eds.), Handbook of qualitative research (2nd ed., pp. 851869). Thousand Oaks, CA: Sage.

Cieurzo, C., \& Keitel, M. A. (1999). Ethics in qualitative research. In M. Kopala \& L. A. Suzuki (Eds.), Using qualitative methods in psychology (pp. 63-75). Thousand Oaks, CA: Sage.

Creswell, J. W. (1998). Qualitative inquiry and research design: Choosing among five traditions. Thousand Oaks, CA: Sage.

Cushing, F. (1920). Zuni breadstuff. New York: Museum of the American Indian.

Denzin, N. K., \& Lincoln, Y. S. (Eds.). (1994). Handbook of qualitative research. Thousand Oaks, CA: Sage.

Denzin, N. K., \& Lincoln, Y. S. (Eds.). (2000a). Handbook of qualitative research (2nd ed.). Thousand Oaks, CA: Sage.

Denzin, N. K., \& Lincoln, Y. S. (2000b). Introduction: The discipline and practice of qualitative research. In N. K. Denzin \& Y. S. Lincoln (Eds.), Handbook of qualitative research (2nd ed., pp. 1-29). Thousand Oaks, CA: Sage.

Fantuzzo, J., McWayne, C., \& Bulotsky, R. (2003). Forging strategic partnerships to advance mental health science and practice for vulnerable children. School Psychology Review, 32, 17-37.

Fassinger, R. E. (2005). Paradigms, praxis, problems, and promise: Grounded theory in counseling psychology research. Journal of Counseling Psychology, 52, 156-166.

Fontana, A., \& Frey, J. H. (2000). The interview: From structured questions to negotiated text. In N. K. Denzin \& Y. S. Lincoln (Eds.), Handbook of qualitative research (2nd ed., pp. 645-672). Thousand Oaks, CA: Sage.

Geertz, C. (1973). Interpretations of culture. New York: HarperCollins.

Haverkamp, B. E. (2005). Ethical perspectives on qualitative research in applied psychology. Journal of Counseling Psychology, 52, 146-155.

Hoshmand, L. T. (2005). Narratology, cultural psychology, and counseling research. Journal of Counseling Psychology, 52, 178-186.

Israel, B., Shulz, A., Parker, E., \& Becker, A. (1998). Review of community-based research: Assessing partnership approaches to improve public health. Annual Review of Public Health, 19, 173-202.

Kopala, M., \& Suzuki, L. A. (Eds.). (1999). Using qualitative methods in psychology. Thousand Oaks, CA: Sage.

Malinowski, B. (1922). Argonauts of the Western Pacific. New York: Dutton.

Marcus, G. E., \& Fischer, M. M. J. (1999). Anthropology as cultural critique: An experimental moment in the human sciences ( $2 \mathrm{nd}$ ed.). Chicago: University of Chicago Press.

Mattis, J. S., \& Dickerson, G. (Coprincipal investigators). (2001). Speaking exile: Women in the African diaspora oral history project [Grant]. Ann Arbor: University of Michigan, Office of the Vice President for Research.

Maxwell, J. A. (1996). Qualitative research design: An interactive approach. Thousand Oaks, CA: Sage.

Miles, M. B., \& Huberman, A. M. (1994). Qualitative data analysis: An expanded sourcebook (2nd ed.). Thousand Oaks, CA: Sage.

Morrow, S. L. (2005). Quality and trustworthiness in qualitative research in counseling psychology. Journal of Counseling Psychology, 52, 250260.

Pipher, M. (2002). The middle of everywhere: The world's refugees come to our town. New York: Harcourt.

Ponterotto, J. G., Casas, J. M., Suzuki, L. A., \& Alexander, C. M. (Eds.). (2001). Handbook of multicultural counseling (2nd ed.). Thousand Oaks, CA: Sage.

Ryan, G. W., \& Bernard, H. R. (2000). Data management and analysis methods. In N. K. Denzin \& Y. S. Lincoln (Eds.), Handbook of qualitative research (2nd ed., pp. 769-802). Thousand Oaks, CA: Sage.

Sanjek, R. (2002). Ethnography. In A. Barnard \& J. Spencer (Eds.), Encyclopedia of social and cultural anthropology (pp. 193-198). New York: Routledge. 
Seidman, I. (1998). Interviewing as qualitative research: A guide for researchers in education and the social sciences. New York: Teachers College Press.

Spradley, J. (1979). The ethnographic interview. New York: Holt, Rhinehart \& Winston.

Spradley, J. (1980). Participant observation. New York: Holt, Rhinehart \& Winston.

Stewart, A. J. (2003). 2002 Carolyn Sherif award address: Gender, race, and generation in a Midwest high school: Using ethnographically informed methods in psychology. Psychology of Women Quarterly, 27, 1-11.

Suzuki, L. A., Prendes-Lintel, M., Wertlieb, L., \& Stallings, A. (1999). Exploring multicultural issues using qualitative methods. In M. Kopala
\& L. A. Suzuki (Eds.), Using qualitative methods in psychology (pp. 123-133). Thousand Oaks, CA: Sage.

Tedlock, B. (2000). Ethnography and ethnographic representation. In N. K. Denzin \& Y. S. Lincoln (Eds.), Handbook of qualitative research (2nd ed., pp. 455-486). Thousand Oaks, CA: Sage.

Ulysse, G. (2002). Conquering duppies in Kingston: Miss Tiny and me, fieldwork conflicts, and being loved and rescued. Anthropology and Humanism, 27, 10-26.

Received August 23, 2004

Revision received October 14, 2004

Accepted October 27, 2004

\section{Low Publication Prices for APA Members and Affiliates}

Keeping you up-to-date. All APA Fellows, Members, Associates, and Student Affiliates receive-as part of their annual dues-subscriptions to the American Psychologist and APA Monitor. High School Teacher and International Affiliates receive subscriptions to the APA Monitor, and they may subscribe to the American Psychologist at a significantly reduced rate. In addition, all Members and Student Affiliates are eligible for savings of up to $60 \%$ (plus a journal credit) on all other APA journals, as well as significant discounts on subscriptions from cooperating societies and publishers (e.g., the American Association for Counseling and Development, Academic Press, and Human Sciences Press).

Essential resources. APA members and affiliates receive special rates for purchases of APA books, including the Publication Manual of the American Psychological Association, and on dozens of new topical books each year.

Other benefits of membership. Membership in APA also provides eligibility for competitive insurance plans, continuing education programs, reduced APA convention fees, and specialty divisions.

More information. Write to American Psychological Association, Membership Services, 750 First Street, NE, Washington, DC 20002-4242. 